\title{
Establishment of exercise intensity for patients with chronic heart failure equivalent to anaerobic threshold based on 6-minute walking test
}

\author{
Qian Luo", Congcong Li", Bo Zhuang", Guanghe Li, Lin Luo, Yi Ni, Zhaoqi Huang, Lemin Wang, \\ Haoming Song, Wenwen Yan, Yuqin Shen
}

Department of Cardiology, Tongji Hospital Affiliated to Tongji University, Tongji University School of Medicine, Shanghai, China

Contributions: (I) Conception and design: L Wang, Y Shen, Q Luo; (II) Administrative support: Y Shen, W Yan; (III) Provision of study materials or patients: H Song, W Yan, G Li, L Luo, Y Ni, Z Huang; (IV) Collection and assembly of data: Q Luo, C Li, B Zhuang; (V) Data analysis and interpretation: Q Luo, C Li, B Zhuang; (VI) Manuscript writing: All authors; (VII) Final approval of manuscript: All authors.

\#These authors contributed equally to this work.

Correspondence to: Haoming Song; Wenwen Yan; Yuqin Shen. Department of Cardiology, Tongji Hospital Affiliated to Tongji University, 389 Xincun Road, Shanghai, China. Email: songhao-ming@163.com; tj-yww@163.com; sy_1963@126.com.

\begin{abstract}
Background: The study aimed to investigate the relationship between the aerobic exercise intensity determined by 6-minute walking distance (6MWD) and its counterpart based on anaerobic threshold (AT) in chronic heart failure (CHF) individuals for exploring suitable means for CHF exercise rehabilitation.

Methods: We retrospectively analyzed data in patient with $\mathrm{CHF}$, who performed cardiopulmonary exercise test (CPET) and 6-minute walking test (6MWT) uniformly. Anthropometric characteristics, left ventricular ejection fraction (LVEF), and multiple parameters of 6MWT and AT were collected.

Results: The results of the analysis revealed that the 6MWD was correlated with the AT positively [CHF group: $r=0.433$, heart failure with reduced ejection fraction (HFrEF) group: $r=0.395$, heart failure with intermediate ejection fraction (HFmEF) group: $r=0.477$, heart failure with preserved ejection fraction (HFpEF) group: $\mathrm{r}=0.445$; all $\mathrm{P}<0.05]$. The regression analysis showed that the linear equation model developed can predict exercise intensity based on AT (EIAT) by exercise intensity based on 6MWD (EI6MWD), the aerobic exercise intensity based on AT and 6MWD respectively, of CHF patients.

Conclusions: There is a correlation between EI6MWD and EIAT. 74.6-87.4\% of EI6MWD in patients with CHF is equivalent to EIAT. It is feasible to establish the aerobic exercise intensity of patients with CHF equivalent to AT based on 6MWD.
\end{abstract}

Keywords: Exercise rehabilitation; chronic heart failure (CHF); 6-minute walking test (6MWT); cardiopulmonary exercise test (CPET); anaerobic threshold (AT)

Submitted Jan 19, 2020. Accepted for publication Jul 31, 2020.

doi: 10.21037/apm-20-265

View this article at: http://dx.doi.org/10.21037/apm-20-265

\section{Introduction}

Heart failure is the end stage of various heart diseases which has rising morbidity and mortality continue $(1,2)$ and the prevalence increasing with age (3-5), and it is one of the major global health problems (6). Compared with traditional medical treatment, appropriate physical activity and exercise training can improve exercise endurance, quality of life, as well as reduce medical expenses (7-12). The main type of exercise for heart failure is aerobic exercise, and suitable intensity of aerobic exercise is crucial for the effective therapy. Thus, its exercise intensity is the key element. Anaerobic threshold (AT) is directly measured by the cardiopulmonary exercise test (CPET). It has been proved safe and effective to establish aerobic exercise 
intensity by the AT (13).

CPET is considered the "gold standard" for assessing aerobic capacity. Peak oxygen uptake (peak $\mathrm{VO}_{2}$ ) and $\mathrm{AT}$ are frequently assessed CPET variables in chronic heart failure (CHF) (14). Unfortunately, the cost of the examination, complicated operation and difficult analysis may render the CPET unfeasible for primary hospitals.

Six-minute walking test (6MWT), as a kind of submaximal test, which is simple, low-cost and convenient to administer without the need of sophisticated equipment $(15,16)$, objectively evaluates a patient's functional capacity (17). Moreover, $6 \mathrm{MWT}$ has been proved to be suitable for prescribing exercise intensity in most people with chronic obstructive pulmonary disease (COPD), and $80 \% 6 \mathrm{MWT}$ average speed is likely to result in training benefits in some cases (18). Since it can assess cardiopulmonary function, prescribe exercise intensity, $6 \mathrm{MWT}$ has been used as part of assessment for CHF patients (19).

Due to great limitations of CPET, 6MWT is suitable for basic hospitals. Unfortunately, the study of the AT exercise intensity in patients with CHF has not been established with $6 \mathrm{MWD}$. Therefore, this study aimed to investigate the relationship between $6 \mathrm{MWD}$ and AT, explore the feasibility of applying 6MWD to determine the aerobic exercise intensity that matched with AT in patients with CHF. We present the following article in accordance with the STROBE reporting checklist (available at http://dx.doi. org/10.21037/apm-20-265).

\section{Methods}

\section{Study population}

The study originated from a retrospective chart analysis of $\mathrm{CHF}$ and non-CHF people, who had completed CPET and 6MWT performed at the Cardiac Rehabilitation Center of Tongji Hospital in Shanghai, from June 2016 to December 2018. CHF patients meet the criteria as follows: aging from 18 to 75 years old, having heart failure symptoms and signs remaining stable for more than 2 weeks, B-type natriuretic peptide $(\mathrm{BNP})>35 \mathrm{pg} / \mathrm{mL}$ or $\mathrm{N}$-terminal pro-BNP $(\mathrm{NT}$ pro $\mathrm{BNP})>125 \mathrm{pg} / \mathrm{mL}$, and having left ventricular systolic or diastolic dysfunction (6). Inclusion criteria of nonCHF people are as follows: aging from 18 to 75 years old, CPET and 6MWT were completed in the Heart Rehabilitation Center of Shanghai Tongji hospital, no symptoms and signs of heart failure and no abnormalities in left ventricular systolic or diastolic function. Patients with pulmonary disease, early acute coronary syndrome (within 2 days), unstable angina, uncontrolled hypertension, high atrioventricular block, acute myocarditis and pericarditis, or symptoms of aortic stenosis severe hypertrophic obstructive cardiomyopathy, acute systemic disease, intracardiac thrombosis were excluded (20). A steady staff team consisting of a well-informed sole-duty cardiologist and two experienced physiotherapists was needed in the process, where the cardiologist was responsible for diagnosis and worked with physiotherapists to conduct $6 \mathrm{MWT}$ and CPET safely. The study was conducted in accordance with the Declaration of Helsinki (as revised in 2013) and was approved by the Ethics Committee of Tongji Hospital Affiliated to Tongji University [LL(H)-08-04]. Informed consent was taken from all the patients.

The study involving 941 patients aged $18-75$ years that performed CPET between June 2016 and December 2018, and 711 patients who completed the 6MWT within 1 day before and after the examination. Among them, 320 patients had echocardiographic data within 1 day before the examination. Coupled with echocardiography, a total of 107 patients had HF were screened by reviewing medical records and testing system. Among them, 33 patients had ejection fraction (EF) $<40 \%$ for heart failure with reduced ejection fraction (HFrEF) and had HF symptoms and/or signs, 23 patients had $50 \%>\mathrm{EF} \geq 40 \%$ for heart failure with intermediate ejection fraction (HFmEF) diagnosis, 51 patients had $\mathrm{EF} \geq 50 \%$ for heart failure with preserved ejection fraction (HFpEF) diagnosis. Thirty-four cases were excluded (all EFs were $>50 \%$ but no data for diagnosis of diastolic heart failure) and one case (no AT). Finally, check the electronic medical records to improve detailed diagnosis, auxilia5ry examination, body mass index (BMI) and drugs. Figure 1 is the flow chart.

\section{$6 M W D$}

6MWD was performed according to the guidelines of the American Thoracic Society (17). The 6MWT was performed indoors, along a long, flat, and straight corridor. Patients were instructed to walk back and forth on a self-chosen walking speed. Running was not allowed. If needed, patients were allowed to slow down the pace or to stop, but were encouraged to resume walking as soon as they were able to. The hallway is 30 meters long. The length of the corridor is marked every 3 meters. 


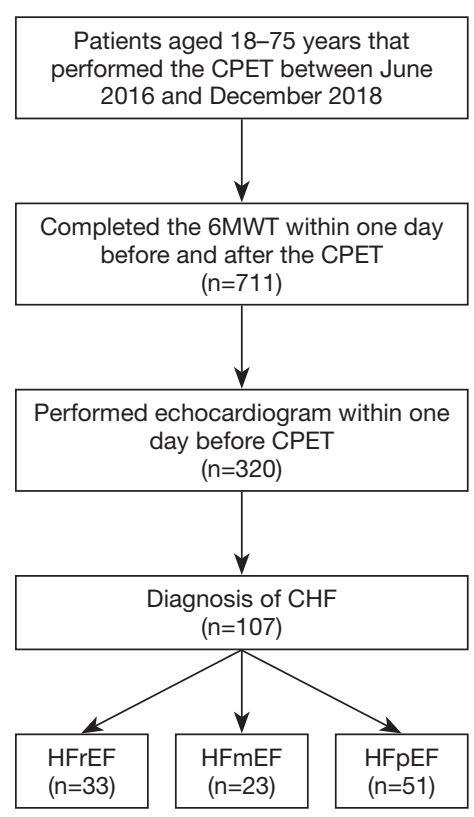

Figure 1 Flow chart of the study. CPET, cardiopulmonary exercise test; CHF, chronic heart failure; HFrEF, heart failure with reduced ejection fraction; HFmEF, heart failure with intermediate ejection fraction; HFpEF, heart failure with preserved ejection fraction.

The turnaround points are marked with a cone (such as an orange traffic cone). A starting line, which marks the beginning and end of each 60-meter lap, is marked on the floor using brightly colored tape. All patients were guided by a uniform standard recording during the test. According to the results, the intensity of aerobic exercise is determined. Before and after the test, were measured. The exercise intensity based on $6 \mathrm{MWD}\left(\mathrm{EI}_{6 \mathrm{MWD}}\right)$, is equal to $6 M W D \times 10 / 1,000(\mathrm{~km} / \mathrm{h})$. For example, the $6 M W D$ result of patient is $350 \mathrm{~m}$, then the exercise intensity is $3.5 \mathrm{~km} / \mathrm{h}$.

\section{Cardiopulmonary exercise testing}

CPET was completed at cardiac rehabilitation center. In this study we used the MasterScreen series of the lung function test system produced by CareFusion of Germany, the Cardiosoft motion test system produced by GE Medical of Germany, and the Viasprint 150 electric bicycle produced by ergoline of Germany. The revised Ramp10 program was adopted, rest on the cycle for 3 minutes, cycle for 3 minutes under no load, and then start from $0 \mathrm{~J} /$ second, increase $5 \mathrm{~J}$ every 30 seconds until the patient reaches a peak of exercise or the end of exercise. Before and after the test, blood pressure, heart rate, pulse oxygen saturation and expired gases were continuously monitored. Gas exchanged was also analyzed during exercise: each exhaled gas is continuously monitored by the pulmonary function test system after the start of the patient test. The anaerobic metabolic threshold was determined by the V-slope method (21). The aerobic exercise intensity determined by $\mathrm{AT}$ was $\mathrm{EI}_{\mathrm{AT}}$, and according to the results, the metabolic equivalent value was obtained by converting the oxygen consumption amount of one metabolic equivalent $(1 \mathrm{MET}=3.5 \mathrm{~mL} / \mathrm{kg} / \mathrm{min}), \mathrm{EI}_{\mathrm{AT}}=$ $($ METs@AT-1) $\times 3.5 \times 60 / 100(\mathrm{~km} / \mathrm{h})(22)$.

\section{Statistical analysis}

Data entry was carried out using the excel (2016 version) software. All analyses were performed using IBM Corp. Released 2016. IBM SPSS Statistics for Windows, Version 24.0. Armonk, NY: IBM Corp software. The data are expressed as mean \pm standard deviation (SD) when normally distributed, and median (interquartile range) $\left[\mathrm{M}\left(\mathrm{P}_{25}, \mathrm{P}_{75}\right)\right]$ if non-normally distributed, and the count variables is displayed by the ratio or composition ratio (\%).

If the measurement data conform to the normal distribution, the correlation analysis used the Pearson accumulation correlation analysis between them. If not, the Spearman analysis was used. Correlation analysis, between the disordered variables (gender) and the measurement data, was analyzed by independent sample $T$ inspection; the classification disorder (sex) was analyzed by chi-square test. Testing was performed two-sided, and statistical significance was defined as $\mathrm{P}<0.05$.

\section{Results}

\section{Demographic and clinical characteristics}

The baseline clinical patients' characteristics are shown in Table 1. In total,107 patients with CHF were enrolled in the study, 95 males and 12 females were included, at a median age of 62.00 years old, median height of $171.00 \mathrm{~cm}$, median weight $75.00 \mathrm{~kg}$, median BMI of $25.71 \mathrm{~kg} / \mathrm{m}^{2}$. The disease consisted of 71 cases of coronary heart disease (CAD), 16 cases with dilated cardiomyopathy (DCM), 7 cases with hypertrophic cardiomyopathy (HCM), 5 cases with valvular heart disease, 8 cases with hypertension (HBP). Heart failure classification: 33 patients with $\mathrm{HFrEF}$ (31 males and 2 females), 23 patients with HFmEF (22 males and 1 female), and 51 patients with HFpEF (42 males and 
Table 1 Characteristics of patients with CHF

\begin{tabular}{|c|c|c|c|c|}
\hline Characteristics & CHF group $(n=107)$ & HFrEF group $(n=33)$ & HFmEF group $(n=23)$ & HFpEF group $(n=51)$ \\
\hline Male, n (\%) & 95 (88.79) & 31 (93.94) & 22 (95.65) & $42(82.35)$ \\
\hline Female, n (\%) & $12(11.21)$ & $2(6.06)$ & $1(4.35)$ & $9(17.65)$ \\
\hline Age & $62.00(55.00,66.00)$ & $58.00(45.50,66.00)$ & $60.00(54.00,70.00)$ & $63.00(58.00,66.00)$ \\
\hline Weight (kg) & $75.00(66.00,84.00)$ & $72.00(61.75,87.50)$ & $76.00(69.00,84.50)$ & $75.00(67.00,80.00)$ \\
\hline BMI $\left(\mathrm{kg} / \mathrm{m}^{2}\right)$ & $25.71(23.36,27.60)$ & $25.26(22.01,29.44)$ & $25.80(24.49,27.28)$ & $25.65(23.36,27.13)$ \\
\hline LVEF, \% & $48.00(38.00,66.00)$ & $33.00(26.00,35.50)$ & $44.00(42.00,48.00)$ & $66.00(59.00,70.00)$ \\
\hline \multicolumn{5}{|l|}{ Disease, n (\%) } \\
\hline HBP & $8(7.48)$ & $2(6.06)$ & 0 & $6(11.76)$ \\
\hline $\mathrm{HCM}$ & $7(6.54)$ & 0 & 0 & $7(13.73)$ \\
\hline Valvular disease & $5(4.67)$ & $1(3.03)$ & $1(4.34)$ & $3(5.88)$ \\
\hline
\end{tabular}

The measurement data in the table are $\mathrm{M}\left(\mathrm{P}_{25}, \mathrm{P}_{75}\right)$. CHF, chronic heart failure; HFrEF, heart failure with reduced ejection fraction; HFmEF, heart failure with intermediate ejection fraction; HFpEF, heart failure with preserved ejection fraction; BMI, body mass index; LVEF, left ventricular ejection fraction; CAD, coronary heart disease; DCM, dilated cardiomyopathy; HBP, hypertension; HCM, hypertrophic cardiomyopathy.

9 females).

\section{MWT and CPET results}

The correlations between the $\mathrm{VO}_{2} \mathrm{AT}$, peak $\mathrm{VO}_{2}$, load AT and load peak in group HFrEF were significantly lower than those in group HFpEF $(\mathrm{P}<0.05)$, whereas there were no significant differences in $6 \mathrm{MWD}$ and $\mathrm{VE} / \mathrm{VCO}_{2}$ slope in CHF sub-groups ( $\mathrm{P}>0.05)$ (Table 2).

\section{Correlation between 6MWD and AT}

A single-factor linear correlation analysis was performed between 6MWD and AT (Table 3). The results showed that there were positive correlations between $6 \mathrm{MWD}$ and $\mathrm{AT}$ in $\mathrm{CHF}$ and each $\mathrm{CHF}$ sub-group respectively. CHF group: $\mathrm{r}=0.433, \mathrm{P}<0.01$; HFrEF group: $\mathrm{r}=0.395, \mathrm{P}=0.023$; HFmEF group: $\mathrm{r}=0.477, \mathrm{P}=0.021$; HFpEF group: $\mathrm{r}=0.445, \mathrm{P}=0.001$.

\section{Correlation between $\mathbf{E I}_{6 M W D}$ and $E \boldsymbol{I}_{A T}$}

Multiple linear regression analysis was performed on
CHF group and each sub-group. There was significant correlation between $\mathrm{EI}_{\mathrm{AT}}$ and $\mathrm{EI}_{6 \mathrm{MWD}}$ in each group (CHF group: $r=0.465$, HFrEF group: $r=0.428$, HFmEF group: $\mathrm{r}=0.600$, HFpEF group: $\mathrm{r}=0.446, \mathrm{P}<0.01)$. Among them, $\mathrm{EI}_{\mathrm{AT}}$ in CHF group was correlated with age $(\mathrm{r}=0.205)$ and left ventricular ejection fraction (LVEF) $(r=0.200)(\mathrm{P}<0.05)$, and $\mathrm{EI}_{\mathrm{AT}}$ in HFrEF group was also correlated with age $(r=0.550, P=0.001)$. The following regression equations were obtained: $\mathrm{CHF}$ group: $\mathrm{EI}_{\mathrm{AT}}=0.810 \times \mathrm{EI}_{6 \mathrm{MWD}}+0.029 \times$ age $+1.863 \times$ LVEF; HFrEF group: $\mathrm{EI}_{\mathrm{AT}}=0.746 \times \mathrm{EI}_{6 \mathrm{MWD}}+$ $0.067 \times$ age; $\mathrm{HFmEF}$ group: $\mathrm{EI}_{\mathrm{AT}}=0.766 \times \mathrm{EI}_{6 \mathrm{MWD}} ; \mathrm{HFpEF}$ group: $\mathrm{EI}_{\mathrm{AT}}=0.874 \times \mathrm{EI}_{6 \mathrm{MWD}}($ Tables 4,5$)$.

\section{Standardized regression coefficients between $E I_{6 M W D}$ and $E I_{A T}$}

The U-test was utilized to compare the standardized regression coefficients of $\mathrm{EI}_{6 \mathrm{MWD}}$ and $\mathrm{EI}_{\mathrm{AT}}$ (Table 6). The results showed that the correlation coefficient between the heart failure groups and the non-heart failure group was statistically different $(\mathrm{P}=0.033)$, and the $\mathrm{CHF}$ sub-groups were not statistically different $(\mathrm{P}>0.05)$. There is a moderate 


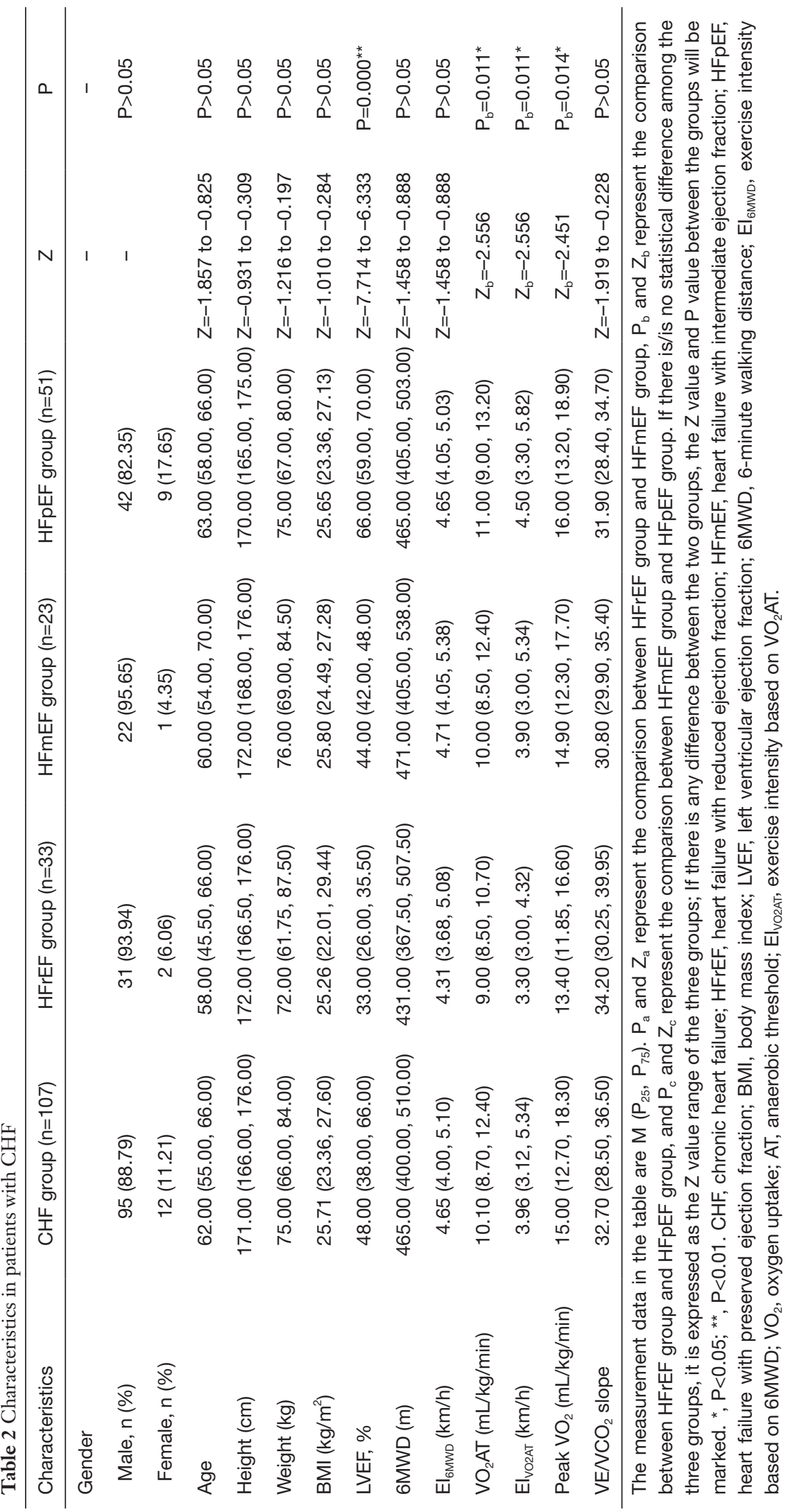


Table 3 Single factor linear correlation analysis results with AT

\begin{tabular}{|c|c|c|c|c|c|c|c|c|}
\hline Independent variable & \multicolumn{2}{|c|}{ CHF group } & \multicolumn{2}{|c|}{ HFrEF group } & \multicolumn{2}{|c|}{ HFmEF group } & \multicolumn{2}{|c|}{ HFpEF group } \\
\hline 6MWD & 0.433 & $0.000^{\star *}$ & 0.395 & 0.023 & 0.477 & 0.021 & 0.445 & 0.001 \\
\hline
\end{tabular}

**, $\mathrm{P}<0.01$. AT, anaerobic threshold; $\mathrm{CHF}$, chronic heart failure; HFrEF, heart failure with reduced ejection fraction; HFmEF, heart failure with intermediate ejection fraction; HFpEF, heart failure with preserved ejection fraction; 6MWD, 6-minute walking distance.

Table 4 Multiple linear regression analysis results with $\mathrm{EI}_{\mathrm{AT}}$

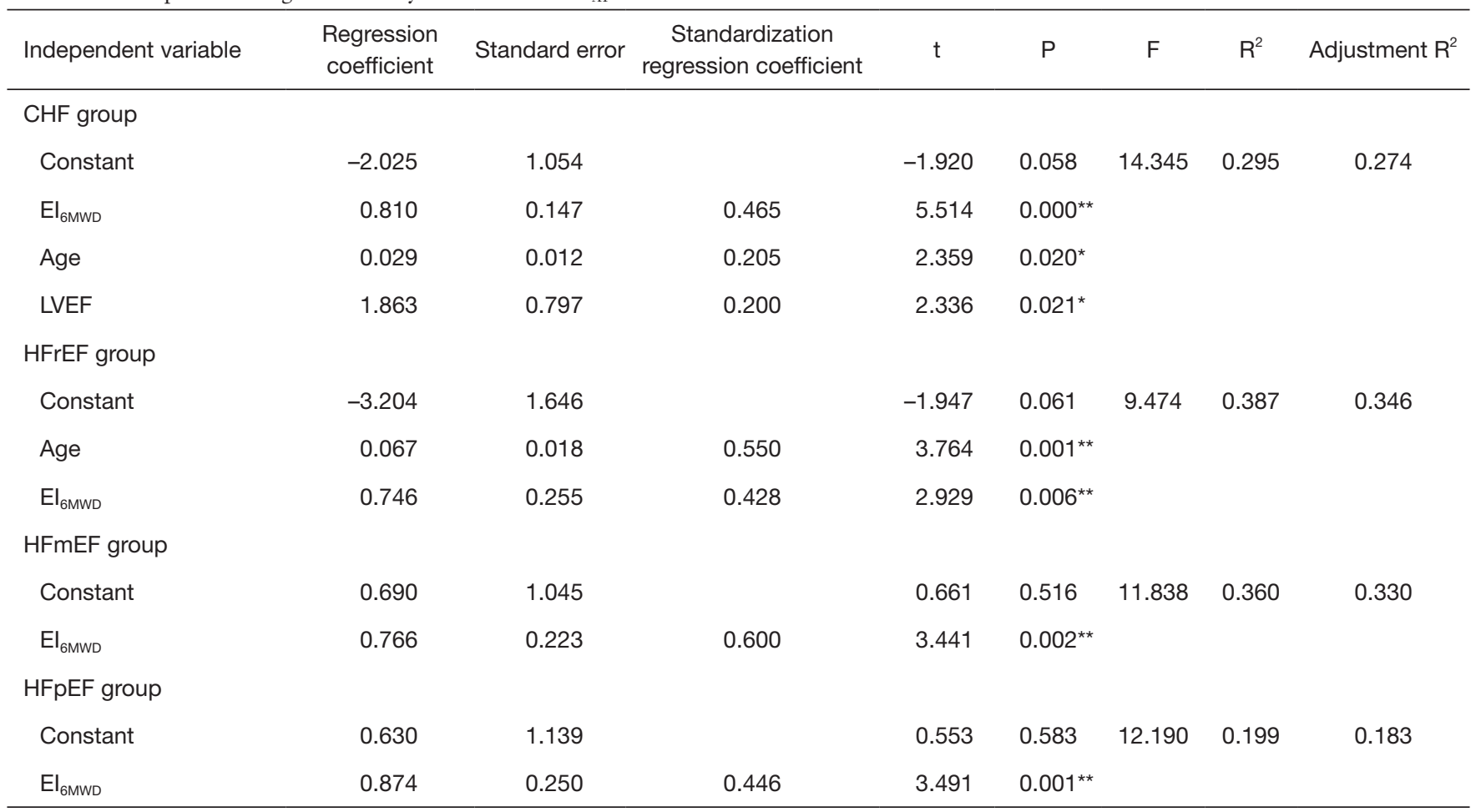

*, $\mathrm{P}<0.05$; ${ }^{* *}, \mathrm{P}<0.01$. AT, anaerobic threshold; $\mathrm{El}_{\mathrm{AT}}$, exercise intensity based on $\mathrm{AT} ; \mathrm{CHF}$, chronic heart failure; 6MWD, 6-minute walking distance; $\mathrm{El}_{6 \mathrm{MWD}}$, exercise intensity based on 6MWD; LVEF, left ventricular ejection fraction; HFrEF, heart failure with reduced ejection fraction; HFmEF, heart failure with intermediate ejection fraction; HFpEF, heart failure with preserved ejection fraction.

positive correlation between $6 \mathrm{MWD}$ and $\mathrm{AT}$ in patients with CHF.

\section{Discussion}

Previous studies were able to show the relationship between $6 \mathrm{MWD}$ and peak $\mathrm{VO}_{2}$. According to the Robert M. Ross studies, there was an equation: peak $\mathrm{VO}_{2}(\mathrm{~mL} / \mathrm{kg} / \mathrm{min})=$ $4.948+0.023 \times 6 \mathrm{MWD}$ (meters) (23). Furthermore, the study of Adedoyin RA showed an equation might be useful when sophisticated equipment is lacking: peak $\mathrm{VO}_{2}=$ $0.0105 \times 6 \mathrm{MWD}$ (meters) $+0.0238 \times$ age $(\mathrm{yr})-0.03085 \times$ weight $(\mathrm{kg})+5.598(24)$. In addition, previous study that suggest the use of the 6MWT to evaluate exercise capacity in patients with heart failure is highly dependent on the degree of functional impairment (25). Individuals who peak $\mathrm{VO}_{2}>25.2 \mathrm{~mL} / \mathrm{kg} / \mathrm{min}, 6 \mathrm{MWT} \mathrm{VO}_{2}$ was significantly lower compared with CPET peak $\mathrm{VO}_{2}$, whereas individuals who peak $\mathrm{VO}_{2} \leq 17.5 \mathrm{~mL} / \mathrm{kg} / \mathrm{min}$ showed significantly higher 6MWT $\mathrm{VO}_{2}$ compared with CPET peak $\mathrm{VO}_{2}$. However, the correlation between aerobic exercise intensity of 6MWT and CPET has not been explored. In this study, we discussed the relationship between $\mathrm{EI}_{6 \mathrm{MWD}}$ and $\mathrm{EI}_{\mathrm{AT}}$, detected by $6 \mathrm{MWT}$ and CPET respectively, and obtained 
Table 5 Excluded variables

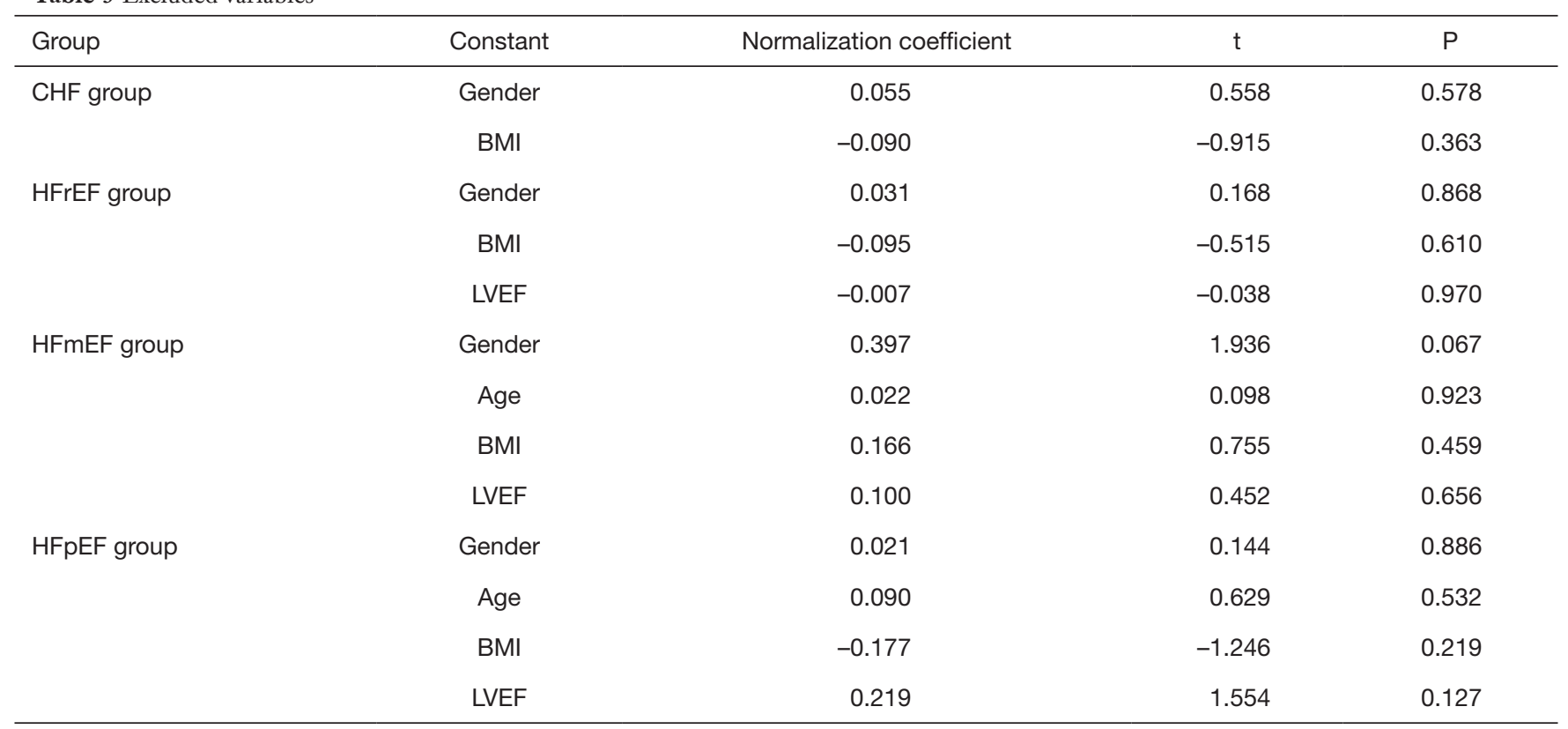

CHF, chronic heart failure; HFrEF, heart failure with reduced ejection fraction; HFmEF, heart failure with intermediate ejection fraction; HFpEF, heart failure with preserved ejection fraction; BMI, body mass index; LVEF, left ventricular ejection fraction.

Table 6 Comparison of standardized regression coefficients between EI6MWD and EIAT

\begin{tabular}{|c|c|c|c|c|}
\hline Group & $\mathrm{N}$ & $\beta$ & Z & $\mathrm{P}$ \\
\hline CHF group vs. HFmEF group & 107 vs. 23 & 0.465 vs. 0.600 & -0.776 & 0.219 \\
\hline CHF group vs. HFpEF group & 107 vs. 51 & 0.465 vs. 0.446 & 0.802 & 0.211 \\
\hline HFrEF group vs. HFmEF group & 33 vs. 23 & 0.428 vs. 0.600 & -0.816 & 0.207 \\
\hline HFmEF group vs. HFpEF group & 23 vs. 51 & 0.600 vs. 0.446 & 0.802 & 0.211 \\
\hline
\end{tabular}

$\mathrm{N}$ is the number of cases, and $\beta$ is the normalized regression coefficient. 6MWD, 6-minute walking distance; $\mathrm{El}_{6 \mathrm{MWD}}$, exercise intensity based on 6MWD; AT, anaerobic threshold; $\mathrm{EI}_{\mathrm{AT}}$, exercise intensity based on $\mathrm{AT}$; $\mathrm{CHF}$, chronic heart failure; HFrEF, heart failure with reduced ejection fraction; HFmEF, heart failure with intermediate ejection fraction; HFpEF, heart failure with preserved ejection fraction.

the specific equation between them as follows.

The results of this study showed that $6 \mathrm{MWD}$ and AT were significantly correlated in patients with CHF. There was no significant difference of case number, age composition, and sex ratio among $\mathrm{CHF}$ sub-groups $(\mathrm{P}>0.05)$ (Table 2). The AT and peak $\mathrm{VO}_{2}$ of $\mathrm{HFrEF}$ patients were lower than those of HFpEF patients $(\mathrm{P}<0.05)$. The exercise tolerance of $\mathrm{HFrEF}$ patients was worse than HFpEF patients. However, there was no significant difference in $\mathrm{VE} / \mathrm{VCO}_{2}$ slope among sub-groups $(\mathrm{P}>0.05)$, indicating that there was no significant difference in ventilation efficiency among the sub-groups. The single factor linear regression analysis showed that there were different degrees of positive correlations between 6MWD and AT in the CHF group and each CHF sub-group respectively. Further linear regression analysis showed that the $\mathrm{EI}_{\mathrm{AT}}$ of $\mathrm{CHF}$ group and each CHF sub-group were positively correlated with $\mathrm{EI}_{6 \mathrm{MWD}}$, and the regression equation was obtained: (I) CHF group: $\mathrm{EI}_{\mathrm{AT}}=0.810 \times \mathrm{EI}_{6 \mathrm{MWD}}+0.029 \times$ age $+1.863 \times \mathrm{LVEF}$; (II) $\mathrm{HFrEF}$ group: $\mathrm{EIAT}=0.746 \times \mathrm{EI}_{6 \mathrm{MWD}}+0.067 \times$ age; (III) HFmEF group: $\mathrm{EI}_{\mathrm{AT}}=0.766 \times \mathrm{EI}_{6 \mathrm{MWD}}$; (IV) $\mathrm{HFpEF}$ group: $\mathrm{EI}_{\mathrm{AT}}=0.874 \times \mathrm{EI}_{6 \mathrm{MWD}}$. The previous equation 
showed that there was a positive correlation between $\mathrm{EI}_{6 \mathrm{MWD}}$ and $\mathrm{EI}_{\mathrm{AT}}$, and the linear equation model developed can predict $\mathrm{EI}_{\mathrm{AT}}$ by $\mathrm{EI}_{6 \mathrm{MWD}}$, the aerobic exercise intensity based on AT and 6MWD respectively, of CHF patients. In other words, it is feasible to establish the aerobic exercise intensity of patients with CHF equivalent to AT based on $6 \mathrm{MWD}$, the distance of 6-minute walk test.

Exercise rehabilitation is gradually attracting the attention of the world (26), and is recommended by the American College of Cardiology at the class IA level (27). The core of exercise rehabilitation in patients with heart failure is exercise intensity. Our team's previous study (13) showed that it is safe and effective for patients with heart failure to exercise at the intensity of the AT. However, the high cost of the technique and the examination is mostly carried out in tertiary hospitals may limit access to primary hospital. Therefore, it is urgent to explore a suitable technique for easily formulating aerobic exercise prescriptions for patients with heart failure in primary hospital where there are a large number of heart failure, so that patients with mild and/or stable heart failure can obtain the same aerobic exercise rehabilitation as in tertiary hospitals. 6MWT is a sub-maximal exercise test and is easy to conduct. The correlation between the exercise intensity of 6MWT and CPET was studied in this study, and a significant conclusion was preliminarily obtained. Thus, it is feasible to use $6 \mathrm{MWT}$ to determine the exercise intensity.

We innovatively put forward the possibility of using 6MWD to develop the exercise intensity equivalent of the AT in primary hospital, through the equations as follows, $\mathrm{CHF}$ group: $\mathrm{EI}_{\mathrm{AT}}=0.810 \times \mathrm{EI}_{6 \mathrm{MWD}}(\mathrm{km} / \mathrm{h})+0.029 \times$ age $(\mathrm{yr})+$ $1.863 \times$ LVEF $(\%)$, HFrEF group: $\mathrm{EI}_{\mathrm{AT}}=0.746 \times \mathrm{EI}_{6 \mathrm{MWD}}$ $(\mathrm{km} / \mathrm{h})+0.067 \times$ age $(\mathrm{yr}), \mathrm{HFmEF}$ group: $\mathrm{EI}_{\mathrm{AT}}=0.766 \times$ $\mathrm{EI}_{6 \mathrm{MWD}}(\mathrm{km} / \mathrm{h}), \mathrm{HFpEF}$ group: $\mathrm{EI}_{\mathrm{AT}}=0.874 \times \mathrm{EI}_{6 \mathrm{MWD}}(\mathrm{km} / \mathrm{h})$. The exercise intensity of CHF patients, determined by $6 \mathrm{MWD}$, the distance of $6 \mathrm{WMT}$, is equivalent to AT intensity, which makes it possible for primary hospitals to carry out safe and effective cardiac rehabilitation with 6MWT.

\section{Study limitations}

The present study has some limitations that should be addressed. On the basis of strict inclusion criteria and exclusion criteria, the sample size was small. However, these findings are preliminary and must be evaluated in a larger patient population. Thus, our team will carry out further research to make the test results more convincing later.
Furthermore, $\mathrm{VO}_{2}$ of the blood system can be influenced, such as hemoglobin, can lead to a decrease in $\mathrm{VO}_{2}(27)$, and creatinine can affect blood hydrogen ion and carbon dioxide partial pressure (28). Therefore, these two indicators need to be considered in the follow-up study.

In conclusion, we demonstrate that there is a correlation between $\mathrm{EI}_{6 \mathrm{MWD}}$ and $\mathrm{EI}_{\mathrm{AT}} \cdot 74.6-87.4 \%$ of $\mathrm{EI}_{6 \mathrm{MWD}}$ in patients with $\mathrm{CHF}$ is equivalent to $\mathrm{EI}_{\mathrm{AT}}$. Therefore, it is feasible to use $6 \mathrm{MWT}$ as a suitable technique for the rehabilitation of patients with $\mathrm{CHF}$ in primary hospitals. However, these findings should be further confirmed in a larger population.

\section{Acknowledgments}

Funding: This study was supported by the National Natural Science Foundations (No. 81974359 and No. 81700316) and the Advanced Proper Technology Promotion Project of Municipal Health and Health Commission in Shanghai, China (No. 2019SY014).

\section{Footnote}

Reporting Checklist: The authors have completed the STROBE reporting checklist. Available at http://dx.doi. org/10.21037/apm-20-265

Data Sharing Statement: Available at http://dx.doi. org/10.21037/apm-20-265

Peer Review File: Available at http://dx.doi.org/10.21037/ apm-20-265

Conflicts of Interest: All authors have completed the ICMJE uniform disclosure form (available at http://dx.doi. org/10.21037/apm-20-265). The authors have no conflicts of interest to declare.

Ethical Statement: The authors are accountable for all aspects of the work in ensuring that questions related to the accuracy or integrity of any part of the work are appropriately investigated and resolved. The study was conducted in accordance with the Declaration of Helsinki (as revised in 2013) and was approved by the Ethics Committee of Tongji Hospital Affiliated to Tongji University [LL(H)08-04]. Informed consent was taken from all the patients.

Open Access Statement: This is an Open Access article distributed in accordance with the Creative Commons 
Attribution-NonCommercial-NoDerivs 4.0 International License (CC BY-NC-ND 4.0), which permits the noncommercial replication and distribution of the article with the strict proviso that no changes or edits are made and the original work is properly cited (including links to both the formal publication through the relevant DOI and the license). See: https://creativecommons.org/licenses/by-nc-nd/4.0/.

\section{References}

1. Chen WW, Wang W, Sui H, et al. Interpretation of key points in china cardiovascular disease report 2016. Chin J Hypert 2017;25:605-8.

2. Guazzi M, Adams V, Conraads V, et al. EACPR/AHA Scientific Statement. Clinical recommendations for cardiopulmonary exercise testing data assessment in specific patient populations. Circulation 2012;126:2261-74.

3. Wang GL, Li RJ, Yang J, et al. Investigation of prevalence and distributing feature of chronic heart failure in middleaged population in Chaoyang District of Beijing. Chin J Med 2015;50:54-7.

4. Yang YN, Ma YT, Liu F. Epidemiological investigation and prevalence of chronic heart failure in Han, Uygur and Kazakhs in Xinjiang. Chin J Cardio 2010;38:460-4.

5. Zhang J, Zhang YH. China heart failure registry studya multicenter, prospective investigation for preliminary analysis on etiology, clinical features and treatment in heart failure patients. Chin Circ J 2015;30:413-6.

6. Ponikowski P, Voors AA, Anker SD, et al. 2016 ESC Guidelines for the diagnosis and treatment of acute and chronic heart failure: The Task Force for the diagnosis and treatment of acute and chronic heart failure of the European Society of Cardiology (ESC). Developed with the special contribution of the Heart Failure Association (HFA) of the ESC. Eur J Heart Fail 2016;18:891-975.

7. Thompson PD, Franklin BA, Balady GJ, et al. Exercise and acute cardiovascular events placing the risks into perspective: a scientific statement from the American Heart Association Council on Nutrition, Physical Activity, and Metabolism and the Council on Clinical Cardiology. Circulation 2007;115:2358-68.

8. Keteyian SJ. Exercise training in congestive heart failure: risks and benefits. Prog Cardiovasc Dis 2011;53:419-28.

9. Belardinelli R, Georgiou D, Cianci G, et al. 10-year exercise training in chronic heart failure: a randomized controlled trial. J Am Coll Cardiol 2012;60:1521-8.

10. O'Connor CM, Whellan DJ, Lee KL, et al. Efficacy and safety of exercise training in patients with chronic heart failure: HF-ACTION randomized controlled trial. JAMA 2009;301:1439-50.

11. Keteyian SJ, Pina IL, Hibner BA, et al. Clinical role of exercise training in the management of patients with chronic heart failure. J Cardiopulm Rehabil Prev 2010;30:67-76.

12. Mediano MFF, Leifer ES, Cooper LS, et al. Influence of baseline physical activity level on exercise training response and clinical outcomes in heart failure: the HF-ACTION trial. JACC Heart Failure 2018;6:1011-9.

13. Shen YQ, Jiang JF, Wang LM, et al. Effects of aerobic exercise on exercise tolerance in patients with chronic heart failure. Zhonghua Yi Xue Za Zhi 2011;91:2678-82.

14. Guazzi M, Myers J, Abella J, et al. The added prognostic value of ventilatory efficiency to the Weber classification system in patients with heart failure. Int J Cardiol 2008;129:86-92.

15. Pulz C, Diniz RV, Alves AN, et al. Incremental shuttle and six-minute walking tests in the assessment of functional capacity in chronic heart failure. Can J Cardiol 2008;24:131-5.

16. Rubim VS, Drumond Neto C, Romeo JL, et al. Prognostic value of the Six-Minute Walk Test in heart failure. Arq Bras Cardiol 2006;86:120-5.

17. ATS Committee on Proficiency Standards for Clinical Pulmonary Function Laboratories. ATS statement: guidelines for the six-minute walk test. Am J Respir Crit Care Med 2002;166:111-7.

18. Zainuldin R, Mackey MG, Alison JA. Prescription of walking exercise intensity from the 6-minute walk test in people with chronic obstructive pulmonary disease. $\mathrm{J}$ Cardiopulm Rehabil Prev 2015;35:65-9.

19. Zielińska D, Bellwon J, Rynkiewicz A, et al. Prognostic value of the six-minute walk test in heart failure patients undergoing cardiac surgery: a literature review. Rehabil Res Pract 2013;2013:965494.

20. American College of Sports Medicine. American College of Sports Medicine's guidelines for exercise testing and prescription. 10th ed. Phliadephia: Wolters Kluwer Health, 2018.

21. Beaver WL, Wasserman K, Whipp BJ. A new method for detecting anaerobic threshold by gas exchange. J Appl Physiol (1985) 1986;60:2020-7.

22. Heath EH. ACSM's Guidelines for exercise testing and prescription, 7th edition. Medicine \& Science in Sports \& Exercise 2010;42:55.

23. Ross RM, Murthy JN, Wollak ID, et al. The six minute 
walk test accurately estimates mean peak oxygen uptake. BMC Pulm Med 2010;10:31.

24. Adedoyin RA, Adeyanju SA, Balogun MO, et al. Prediction of functional capacity during six-minute walk among patients with chronic heart failure. Niger J Clin Pract 2010;13:379-81.

25. Jehn M, Halle M, Schuster T, et al. The 6-min walk test in heart failure: is it a max or sub-maximum exercise test? Eur J Appl Physiol 2009;107:317-23.

26. Morris-Thurgood JA, Frenneaux MP. Pacing in congestive heart failure. Curr Control Trials Cardiovasc Med

Cite this article as: Luo Q, Li C, Zhuang B, Li G, Luo L, Ni Y, Huang Z, Wang L, Song H, Yan W, Shen Y. Establishment of exercise intensity for patients with chronic heart failure equivalent to anaerobic threshold based on 6-minute walking test. Ann Palliat Med 2020;9(5):2766-2775. doi: 10.21037/apm-20265
2000;1:107-14.

27. Yancy CW, Jessup M, Bozkurt B, et al. 2017 ACC/ AHA/HFSA focused update of the 2013 ACCF/AHA guideline for the management of heart failure: a report of the American College of Cardiology/American Heart Association Task Force on Clinical Practice Guidelines and the Heart Failure Society of America. Circulation 2017;136:e137-61.

28. Weber KT, Janicki JS. Cardiopulmonary exercise testing: physiological principles and clinical applications. Philadelphia: W. B. Aaunders, 1986. 